\title{
Associated risk factors with seroprevalence of HIV and HBV co-infection among Pregnant women attending guelendeng health District in the Mayo- kebbi East Region of Chad
}

\begin{abstract}
Background: In Republic of Chad, the seroprevalence of HIV among antenatal pregnant women is known as decreasing over years meanwhile the epidemiological data among pregnant women for hepatitis B virus are scarce. The co-infection HIV/HBV increases the risk of mother to child transmission of both viruses. This study aimed to determine the rate of HIV, HBV co-infection and to identify the associated risk factors among pregnant women attending Guelendeng health district (GHD).
\end{abstract}

Methods: A cross-sectional and descriptive study was conducted from March to May 2019 among pregnant women attending GHD. The questionnaire included demographics, AIDS and HBV knowledge, behavior factors and history of blood transfusion. Blood samples were obtained and tested serologically for HIV and HBV. The study of associations between exposure and outcome variables was sought with the odds ratio (OR), expressed with $95 \%$ confidence interval. Tests were performed using Epi info 7.0 with $\mathrm{p}<0.05$ considered as significant.

Results: Out of 200 enrolled pregnant women, the median age was 25years old with interquartile range from 20.5 to 30 years old. The seroprevalence of HIV, HBV and the coinfection HIV/HBV were 4.5\% (95\% CI: 2.1\%-8.4\%; 9/200), 13\% (95\% CI: 8.7\%-18.5\%; $26 / 200)$ and $2 \%(95 \%$ IC: $0.6 \%-5 \% ; 4 / 200)$ respectively. The antenatal age was associated to HBV infection $(\mathrm{p}=0.04)$ unlike HIV infection $(\mathrm{p}=0.4)$ and HIV/HBV co-infection $(\mathrm{p}=0.52)$. Women aged more than 29 years were most affected. Bivariate analysis identified that the non-use of condom (OR 7.79, 95\% CI: 1.9-32.6, $\mathrm{p}=0.004)$ and blood transfusion history (OR 17.9, 95\% CI: 2.6-124.8, $\mathrm{p}=0.01$ ) were associated risk factors of contracting HIV.

Conclusion: The seroprevalence of HIV and HBV remains high among pregnant women attending antenatal ward in Guelendeng Health District with associated risk factors such as age, blood transfusion and the non-use of condom with new sexual partners.

Keywords: seroprevalence, HIV, HBV, associated risk factors, pregnant women, Chad
Volume 6 Issue 6 - 2020

Salomon Philippe Nguwoh, ${ }^{1,3,7,9}$ Joseph

Fokam, ${ }^{2,8,10}$ Christian Ngounouh Taheu, ${ }^{1,3,9}$ Emmanuel Issembel, ${ }^{4,9}$ joel Ikda Houlbere, ${ }^{4}$ Serges Tchatchouang, ${ }^{5}$ Rodrigue Wouambo Kamga, ${ }^{6}$ Ghislain René Essomba, ${ }^{7,8}$ Roger Somo Moyou, ${ }^{2,8,9}$ Marie Claire Assoumou Okomo ${ }^{7,8}$

'Distant Production House University, Delaware, United State of America

${ }^{2}$ Chantal BIYA International Reference Centre for Research on HIV/AIDS prevention and management, Cameroon

${ }^{3}$ Faculty of Medicine and pharmaceutical Sciences of University of Douala, Higher Institute of Sciences and Techniques Applied to Health, Cameroon

${ }^{4}$ Guelendeng Health District, Cameroon

${ }^{5}$ Department of Biochemistry, University of Yaoundé I,

Cameroon

${ }^{6}$ Department of Microbiology and Parasitology, University of Buea, Cameroon

${ }^{7}$ National Public Health Laboratory, Cameroon

${ }^{8}$ Faculty of Medicine and Biomedical Sciences of the University of Yaoundé I, Cameroon

${ }^{9}$ Faculty of Medicine and pharmaceutical Sciences of University of Douala, Cameroon

${ }^{10}$ University of Buea, faculty of Health Sciences, Cameroon

Correspondence: Christian Ngounouh Taheu, Faculty of Medicine and pharmaceutical Sciences of University of Douala, Higher Institute of Sciences and Techniques Applied to Health, Cameroon, Tel (+237) 677453486/695828686,

Email taheuchristian@gmail.com

Received: November 25, 2020 | Published: December 08, 2020
Abbreviations: AIDS, acquired immunodeficiency syndrom; GHD, Gueledeng health district; CI, confidence interval; DNA, dexoyribonucleic acid; HBV, hepatitis B virus; $\mathrm{HCC}$, hepatocellular carcinoma; $\mathrm{HBeAg}$, hepatitis B envelop antigen; $\mathrm{HBsAg}$, hepatitis B surface antigen; HIV, human immunodeficiency virus; IQR, interquartile range; OR, odds ratio; MTCT, mother-to-child transmission; PLHIV, people living with immunodeficiency virus; SD, standard deviation; STIs, sexual transmitted infections; WHO, World health organization

\section{Introduction}

Human Immunodeficiency Virus (HIV) and Hepatitis B Virus (HBV) infections remain particular health challenge in sub-Saharan Africa. ${ }^{1}$ While HIV affects about 35.3 million people, ${ }^{2}$ World Health Organization (WHO) estimates that about 400 million people worldwide are infected by HBV with high prevalence ( 8 to $15 \%$ ) in
Africa and Asia. ${ }^{1}$ Studies revealed that HBV infection may be present in the two-third of people living with HIV (PLHIV) in sub-Saharan Africa. ${ }^{1}$ Major clinical relevance of this co-infection is that HBVinduced hepatitis in PLHIV leads to higher risk of liver-disease and associated-mortality than reported in HIV mono-infected patients. ${ }^{3,4}$ For HIV, it accelerates progression of $\mathrm{HBV}$ - or $\mathrm{HCV}$-associated chronic liver disease as well as a rapid progression to hepatocellular carcinoma (HCC). ${ }^{5,6}$ Because of shared routes and mechanisms of transmission (blood, sexual, blood transfusion and from mother to child), HBV and HIV co-infection is common among patients..$^{7,8}$ Transmission of HBV from mother to infant during the perinatal period represents an essential link in the maintenance of infection, especially in countries with high endemicity. ${ }^{7}$ This risk is estimated at 10 to $40 \%$ if the mother is a carrier of HBsAg and 70 to $90 \%$ if the $\mathrm{HBe}$ antigen $(\mathrm{HBe} \mathrm{Ag})$ is detected in maternal serum. In the absence of $\mathrm{HBeAg}$ (pre-core mutant), the risk of HBV transmission exists and interpretation must take into account the viremia. ${ }^{9}$ 
Viral hepatitis B during pregnancy is associated with a high risk of maternal and infant complications with a high probability of progression to chronicity and can lead to spontaneous abortion, premature delivery, restrictions intrauterine growth and low birth weight. ${ }^{10}$ Preventive measures had been recommended by the WHO, including the introduction of the HBV vaccine, and the use of immunoglobulin after childbirth. ${ }^{11}$ Given the unavailability of immunoglobulin in health centres in developing countries, vaccination remains the most appropriate means of preventing HBV infection during the perinatal period. ${ }^{12}$ In Chad, the introduction of this vaccine was effective since 2008. However, there are multiple disparities in the geographic coverage between cities and villages. In addition, testing for $\mathrm{HBsAg}$ is not systematic and rarely requested during antenatal consultations. Such a situation of low HBV screening rate among pregnant women could be biases in data reported.

The prevalence of HIV is $1.6 \%$ in the general population and $2.9 \%$ among pregnant women in Chad. ${ }^{13}$ As many sub-Saharan Africa countries, Chad is located in the area of high endemicity for HBV (HBsAg $>8 \%$ ), with an estimated prevalence of $12 \%$ in the general population. However, the epidemiological data relating to HBV infections in pregnant women remain unknown. ${ }^{13}$ Considered as vulnerable population, pregnant women experience physiological disturbances and an additional HIV and/or HBV infection will certainly be felt more heavily.

Considering the seriousness of these infections which can be transmitted from the mother to her foetus and the lack of national data especially that of viral hepatitis B in this vulnerable group of population, studies aiming to determine their seroprevalence are very relevant to plan preventive actions and develop maternal and child health policies. This study will therefore be of paramount importance for the strengthening of programs in prenatal consultation units in Chad. The aim of this study was to determine the seroprevalence of HIV, HBV co-infection and to identify associated risk factors among pregnant women attending Guelendeng Health District in Chad Republic.

\section{Materials and methods}

\section{Study design}

A cross-sectional and descriptive study was conducted from February 10th to May 28th, 2019 at Guelendeng Health District on pregnant women. This health centre is located in the Department of Mayo-Lemié, in the Province of Mayo-Kebbi Est, Chad.

\section{Sample size calculation}

The minimum size of our sample was calculated using the following formula: $n=\left(Z^{\wedge} 2 \times p(1-p)\right) /\left((\varepsilon)^{\wedge} 2\right)$

With " $z "=$ the standard deviation of 1.96 (95\% confidence interval);

"p"=prevalence of HIV among pregnant women in Republic of Chad $(2.9 \%))^{13}$

$$
\text { ' } \varepsilon "=\text { degree of precision (5\%) and "'n"= mimimum sample size. }
$$

Appling this formula we obtained $n=\left(\llbracket(1.96) \rrbracket^{\wedge} 2 \times(0.029) \times(1-\right.$ $0.029)) /\left((0.05) \rrbracket^{\wedge} 2=43.27\right.$

\section{Participant's enrolment}

Pregnant women attending their antennal care at the sentinel site were enrolled after giving their consent. An authorization of health district was obtained, then information sheet was administered to the eligible participants, who then provided their informed consent prior to enrollment into the study. Informed consent from legal representative was obtained for minors' participants (pregnant women under 21 years of age). In addition, a personal interview with those minors was undertaken concerning some sexual practices. Confidentiality was secured by the use of identification codes attributed to each of the study participants.

\section{Demographic, clinical and sexual behavior features}

Data were collected on demographics, AIDS and HBV awareness, sexual behavior, blood transfusion and stage of pregnancy in the standardized questionnaire (additional file 1) that were administrated through face-to-face interviews by the trained physicians. Blood specimens were collected from participants and tested for HIV and HBV infections. Contact information including the phone number of each participant was recorded. All participants were educated in the general information phase on HIV and HBV and trained on how to practice safe sex during pre-test and post-test counseling provided by this study.

\section{Laboratory testing}

A total of $5 \mathrm{~mL}$ of whole blood was collected from each study participant in a dry tube. Serum samples were collected and kept at $-20^{\circ} \mathrm{C}$ until assays of interest were run. HIV screening test was carried out by the HIV $1 / 2$ rapid diagnostic tests (Determine ${ }^{\mathrm{TM}}$ HIV-1 12 , Alere Medical Co., Japan) or SD HIV-1/2 bioline. ${ }^{14}$ Positives HIV tests were then confirmed by OraQuick ${ }^{\circledR}$ Rapid HIV-1/2 Antibody Test (from Orasure Technologies, Inc. Bethlehem, PA 18015 USA) performed with oral fluid, whole blood, serum or plasma. ${ }^{15}$ Testing of HBV was performed by using serological assay strategy as recommended by WHO, ${ }^{16}$ the HBV One Step Rapid Assay DiaSpot ${ }^{\circledR}$ (Jawa Barat, Indonesia) which detects HBsAg. This is a rapid chromatographic immunoassay test strip for visual reading and qualitative detection of HBsAg. ${ }^{17}$

\section{Statistical analysis}

Questionnaires were double-entered and then checked for accuracy using Excel 2013 and analysed in Epi info 7 software. Mean, frequencies and standard deviations were generated to describe the demographic characteristics, AIDS and HBV awareness, behavior characteristics, prevalence of HIV and HBV. Bivariate logistic regression was used to determine the association between the outcome and factors associated variables. The study of associations between the variables was sought with the odds ratio (OR), expressed with $95 \%$ confidence interval. Analyses with $\mathrm{p}<0.05$ were considered as statistically significant.

\section{Results}

\section{Socio-demographic characteristics of the study population}

A total of 200 pregnant women were recruited in this study. The mean age was $26 \pm 6.8$ years old, ranging from 15 to 45 years old and the predominant age group was 22-28years old with $38.50 \%$ (77/200). Seventy seven point five percent $(155 / 200)$ of study participants were married monogamy and 35.5\% (71/200) were illiterate. Among two hundred pregnant women enrolled, $89.5 \%$ (179/200) were housewives, $43 \%(86 / 200)$ were at the $2 \mathrm{nd}$ of gestational age, $66.0 \%$ $(132 / 200)$ were multidelivery and $48.0 \%(96 / 200)$ of them were grand multiparous (Table 1). 
Table I Socio-demographic characteristics of the study population

\begin{tabular}{|c|c|c|c|}
\hline Variables & $\mathbf{N}=\mathbf{2 0 0}$ & $\begin{array}{l}\text { Percentage } \\
(\%)\end{array}$ & $\begin{array}{c}\text { Confidence } \\
\text { Interval }(95 \%)\end{array}$ \\
\hline Age, median [IQR] & & $25[20.50-30]$ & \\
\hline \multicolumn{4}{|l|}{ Age groups (in years) } \\
\hline$|5-2|$ & 61 & 30.5 & $24.2-37.4$ \\
\hline $22-28$ & 77 & 38.5 & $31.7-45.6$ \\
\hline $29-35$ & 38 & 19 & | $3.8-25 . \mid$ \\
\hline $36-45$ & 24 & 12 & $7.4-16.7$ \\
\hline \multicolumn{4}{|l|}{ Educational Status } \\
\hline Illiterate & 71 & 35.5 & $28.9-42.6$ \\
\hline Primary & 58 & 29 & $22.8-35.8$ \\
\hline Secondary & 63 & 31.5 & $25.1-38.4$ \\
\hline University & 8 & 4 & I.7-7.7 \\
\hline \multicolumn{4}{|l|}{ Marital Status } \\
\hline Single & 3 & 1.5 & $0.3-4.3$ \\
\hline Divorced & 6 & 3 & I.I-6.4 \\
\hline Monogamy & 155 & 77.5 & $71.08-83.09$ \\
\hline Polygamy & 36 & 18 & I2.94-24.04 \\
\hline \multicolumn{4}{|l|}{ Occupation } \\
\hline Trader & 8 & 4 & I.7-7.7 \\
\hline Pupil & 8 & 4 & I.7-7.7 \\
\hline Student & 2 & I & $0.1-3.5$ \\
\hline Fonctionary & 3 & 1.5 & $0.3-4.3$ \\
\hline Housewife & 179 & 89.5 & $84.4-93.4$ \\
\hline \multicolumn{4}{|l|}{ Gestational age } \\
\hline Ist trimester & 36 & 18 & $12.9-24.0$ \\
\hline 2nd trimester & 86 & 43 & $36.0-50.2$ \\
\hline $3 r d$ trimester & 78 & 39 & $32.2-46.1$ \\
\hline \multicolumn{4}{|l|}{ Delivery } \\
\hline Multidelivery & 132 & 66 & $58.9-72.5$ \\
\hline Paucidelivery & 29 & 14.5 & $9.9-20.2$ \\
\hline Ist Delivery & 39 & 19.5 & $14.2-25.7$ \\
\hline \multicolumn{4}{|l|}{ Parity } \\
\hline Nulliparous(0) & 46 & 23 & I7.4-29.5 \\
\hline Primiparous(I) & 23 & 11.5 & $7.4-16.7$ \\
\hline Multiparous(2-4) & 35 & 17.5 & $12.5-23.5$ \\
\hline Grand Multiparous(>5) & 96 & 48 & $40.9-55.2$ \\
\hline
\end{tabular}

$\mathrm{IQR}$, interquartile range

\section{Socio-demographic seroprevalence of HIV and HBV co-infection}

Out of 200 pregnant women screened, the seroprevalence of HIV, HBV was respectively $4.5 \%$ (95\% CI: $2.1-8.4 ; 9 / 200) ; 13 \%(95 \%$ CI: $8.7-18.5 ; 26 / 200)$. The rate of HIV/HBV co-infection was $2 \%$ (95\% CI: $0.5-5 ; 4 / 200)$. The prevalence of HIV and HBV infection seemed to increase with age range $(p=0.04)$. No significant socio- demographic characteristics (age groups, marital status, educational status, occupation, gestational age, parity and dilevery) have been identified for HIV and HBV infection. In this study, no sociodemographic characteristics associated to the co-infection HIV/HBV has been found (Table 2).

The majority of study participants declared to have never received an anti-HBV vaccine with $95.5 \%(191 / 200)$ and among them, $12.57 \%$ (24/26) were HBsAg positive. Meanwhile, pregnant women who declared received incomplete vaccination against $\mathrm{HBV}$ where $\mathrm{HBsAg}$ positive with $16.67 \%(1 / 6)$ and $50.0 \%(1 / 2)$ for one dose and two doses respectively $(\mathrm{p}=0.44)$.

\section{Associated risk factors among the study participants}

Bivariate logistic regression analysis identified that history of blood transfusion $(\mathrm{OR}=17.9$ 95\% $\mathrm{CI}$ : $2.6-124.8 ; \mathrm{p}=0.01)$ and the nonsystematical use of condom $(\mathrm{OR}=7.8 ; 95 \% \mathrm{CI}$ : 1.9-32.6; $\mathrm{p}=0.004)$ were significantly associated to HIV infection as shown in the Table 3. Contrarily to HIV, no behavioral factor (awareness of HBV, transfusion, excision, tatoo, use of condom and anti-HBV history) has been associated to HBV infection.

\section{Discussion}

The aim of this study was to determine seroprevalence of HIV, HBV co-infection and to identify associated risk factors among pregnant women in Guelendeng-Health District, Chad. The survey identified a wide distribution of HBV seroprevalence (13\%) compared to HIV $(4.5 \%)$. The national data with HBV seroprevalence of $11.4 \%,{ }^{12}$ higher than that of HIV with $2.9 \%{ }^{18}$ Similar results of HIV seroprevalence have been already found among pregnant women in Chad. ${ }^{19}$ In Chad, unlike HIV, the epidemiological data on HBV among pregnant is scarce or non-existent. But some studies in 2018 reported similar prevalence of $\mathrm{HBV}$ in childbearing women living in Chad. ${ }^{13,20}$ In comparison to other studies carried out in Cameroon, similar finding of HBV and HIV seroprevalence among pregnant women were reported by. ${ }^{21,22}$ The seroprevalence of HBV observed in our study reflects the overall prevalence of HBV in the general population in Chad $(12 \%)^{12}$ and the large gap with HIV seroprevalence could be explained by the fact that it is known that HBV is 50 to 100 times more contagious than HIV. ${ }^{23}$ Indeed, HBV has been found in virtually all body secretions/excretions and unlike HIV, it can survive outside the body for at least 7 days after which the virus can still cause infection. ${ }^{24}$

The co-infection HIV/HBV in this study was $2 \%$ (95\% CI: $0.6-$ 5 ) and it was similar to the results found in studies in the general population in some nearby countries in sub-Saharan Africa such as Cameroon, Rwanda and south Africa where $1.5 \%,{ }^{25} 4.1 \%{ }^{26}$ and $3.1 \%{ }^{27}$ of HIV/HBV co-infections have been reported respectively. From our analyses, the prevalence of HIV and HBV varies geographically and depends on exposure to risks factors. ${ }^{28}$ The seroprevalence of HBV and HIV seemed to be higher among the age group $29-45$ years $(p=0.65$ and 0.19 ). The national statistic program in Chad in 2011 reported a high rate of childbearing age women among HIV positives (5.6\%). ${ }^{29}$ There, young women aged 25-34 years are the most affected by sexual transmitted infections such as HIV and HBV. ${ }^{29}$ Similar results have been found in Cameroon where $70 \%$ of people living with HIV aged between 15-49 years of age are women. ${ }^{30}$ In fact, that age range fit ideally for marriage, pregnancy and thus implies high sexual activity in a country where men with multiple sex partnerare rampant. ${ }^{27}$

The seroprevalence of HIV among pregnant women with primary and secondary level of education was respectively $5.2 \%$ and $7.9 \%(\mathrm{p}$ $=0,29)$. The HBsAg was more detected among pregnant women 
with no educational status than those literate. Previous studies found an association between sexual transmitted infections (STIs) and the educational status. ${ }^{31}$ As more as women are educated, less the prevalence of sexual transmitted infections are. This could explain why education is a key element of communication with patients, of paramount importance in decoding messages during sensitization and communication for behavior change. ${ }^{31}$

Table 2 Socio-demographic characteristics with seroprevalence of HIV and HBV co-infection

\begin{tabular}{|c|c|c|c|c|c|c|c|}
\hline Variables & $\mathbf{N}=$ & HIV+ & $\mathbf{p}$ & HVB+ & $\mathbf{p}$ & HIV/HVB + & $\mathbf{p}$ \\
\hline & 200 & $n=09(\%)$ & & $n=26(\%)$ & & $n=04(\%)$ & \\
\hline \multicolumn{8}{|l|}{ Age groups (in years) } \\
\hline$|5-2|$ & 61 & $01(1.64)$ & 0.4 & $05(8.20)$ & 0.04 & $00(0.00)$ & 0.52 \\
\hline $22-28$ & 77 & $05(6.49)$ & & $09(11.69)$ & & $03(3.90)$ & \\
\hline $29-35$ & 38 & $03(7.89)$ & & $06(15.79)$ & & $01(2.63)$ & \\
\hline $36-45$ & 24 & $00(0.00)$ & & $06(25.00)$ & & $00(0.00)$ & \\
\hline \multicolumn{8}{|l|}{ Educational Status } \\
\hline Illiterate & 71 & $0 \mathrm{I}(\mathrm{I} .4 \mathrm{I})$ & 0.29 & $13(18.31)$ & 0.29 & $00(0.00)$ & 0.25 \\
\hline Primary & 58 & $03(5.17)$ & & $04(6.90)$ & & $0 \mathrm{I}(\mathrm{I} .72)$ & \\
\hline Secondary & 63 & $05(7.94)$ & & $08(12.70)$ & & $03(4.76)$ & \\
\hline University & 8 & $00(0.00)$ & & $0 I(12.50)$ & & $00(0.00)$ & \\
\hline \multicolumn{8}{|l|}{ Marital status } \\
\hline Single & 3 & $00(0.00)$ & 0.06 & $01(33.33)$ & 0.47 & $00(0.00)$ & 0.4 \\
\hline Divorced & 6 & $0 \mathrm{I}(16.67)$ & & $00(0.00)$ & & $00(0.00)$ & \\
\hline Monogamy & 155 & $04(2.58)$ & & $19(12.26)$ & & $02(1.29)$ & \\
\hline Polygamy & 36 & $04(I I . I I)$ & & $06(16.67)$ & & $02(5.56)$ & \\
\hline \multicolumn{8}{|l|}{ Occupation } \\
\hline Trade & 8 & $00(0.00)$ & 0.89 & $00(0.00)$ & 0.71 & $00(0.00)$ & 0.97 \\
\hline Pupil & 8 & $00(0.00)$ & & $0 \mathrm{I}(12.50)$ & & $00(0.00)$ & \\
\hline Student & 2 & $00(0.00)$ & & $00(0.00)$ & & $00(0.00)$ & \\
\hline Fonctionary & 3 & $00(0.00)$ & & $00(0.00)$ & & $00(0.00)$ & \\
\hline Housewife & 179 & $09(5.03)$ & & $25(13.97)$ & & $04(2.23)$ & \\
\hline \multicolumn{8}{|l|}{ Gestational age } \\
\hline Ist trimester & 36 & $0 \mathrm{I}(2.78)$ & 0.34 & $08(22.22)$ & 0.15 & $01(2.78)$ & 0.76 \\
\hline 2nd trimester & 86 & $06(6.98)$ & & $08(9.30)$ & & $01(1.16)$ & \\
\hline $3 r d$ trimester & 78 & $02(2.56)$ & & $10(12.82)$ & & $02(2.56)$ & \\
\hline \multicolumn{8}{|l|}{ Delivery } \\
\hline Multidelivery & 132 & $07(5.30)$ & 0.73 & $18(13.64)$ & 0.85 & $04(3.03)$ & 0.34 \\
\hline Paucidelivery & 29 & 이(3.45) & & $04(13.79)$ & & $00(0.00)$ & \\
\hline Ist Delivery & 39 & OI (2.56) & & $04(10.26)$ & & $00(0.00)$ & \\
\hline \multicolumn{8}{|l|}{ Parity } \\
\hline Nulliparous(0) & 46 & $01(2.17)$ & 0.84 & $05(10.87)$ & 0.39 & $00(0.00)$ & 0.54 \\
\hline Primiparous(I) & 23 & $0 \mathrm{I}(4.35)$ & & $03(13.04)$ & & $00(0.00)$ & \\
\hline Multiparous(2-4) & 35 & $02(5.7 I)$ & & $02(5.7 I)$ & & $01(2.86)$ & \\
\hline Grand Multiparous $(>5)$ & 96 & $05(5.21)$ & & $16(16.67)$ & & $03(3.12)$ & \\
\hline
\end{tabular}

+ , positive; $n$, effective; $\%$, percentage; $p$, p-value 
Table 3 Associated risk factors and HIV infection

\begin{tabular}{|c|c|c|c|c|}
\hline Variables & $\mathbf{N}=\mathbf{2 0 0}$ & HIV+ n=09(\%) & OR(95\%CI) & $\mathbf{p}$ \\
\hline \multicolumn{5}{|c|}{ Knowledge of HIV } \\
\hline No & 25 & $0(0.0)$ & NA & 0.6 \\
\hline Yes & 175 & $09(5.1)$ & & \\
\hline \multicolumn{5}{|c|}{ History of blood transfusion } \\
\hline No & 195 & $07(3.6)$ & $17.9(2.6-124.8)$ & 0.01 \\
\hline Yes & 5 & $02(40)$ & & \\
\hline \multicolumn{5}{|l|}{ Excision } \\
\hline No & 133 & $06(04.5)$ & $0.9(0.2-4.1)$ & 1 \\
\hline Yes & 67 & $03(04.5)$ & & \\
\hline \multicolumn{5}{|l|}{ Tatoo } \\
\hline No & 90 & $03(3.3)$ & I.7(0.4-6.9) & 0.5 \\
\hline Yes & 110 & $06(5.4)$ & & \\
\hline \multicolumn{5}{|c|}{ Use of condom } \\
\hline Never & 155 & $03(1.9)$ & $7.8(1.9-32.6)$ & 0.004 \\
\hline Often & 45 & $06(I 3.3)$ & & \\
\hline
\end{tabular}

+, positive; n, effective; \%, percentage; OR, odds ratio; NA, not applicable; $\mathrm{Cl}$, confidence interval; $p$ : $p$-value.

According to the risk factors, bivariate logistic regression analysis identified that history of blood transfusion and the non-systematical use of condom were significantly associated to HIV infection. Pregnant women with history of blood transfusion had a high chance of 18 times $(40 \%$; OR=17.9 95\%CI: $2.6-124.8 ; \mathrm{P}=0.01)$ to be infected by HIV. The similar result have been reported in Cameroon by ${ }^{21}$ among pregnant women who had a history of blood transfusion (OR: $11 ; 1.60-75.50 ; \mathrm{p}=0.03)$. This result could be explained to the fact that, blood is transfused to pregnant women to replace blood lost during labor and prevent maternal mortality. Alarming fact, pregnant women who declared using condom were more affected by HIV than those not using $(13.3 \%$ versus $1.94, \mathrm{OR}=7.79, \mathrm{p}=0.004)$. Pregnant women who declared having awareness on HIV seemed to be more positive than others. The sensitizations on preventive methods against sexual transmitted infections are vital and depends on countries. In Chad, the barrier in the use of condom is multifactorial depending on religious, geographical, cultural and financial aspects. ${ }^{29}$

\section{Study limitations}

This study has some limitations. The accuracy of detection of active HIV and HBV infection depends on a number of factors such as the screening method used. ${ }^{32}$ Over the years, the sensitivity and specificity of HBV screening tools have improved and this could impact on the difference prevalence rates reported across studies published in different year. So, the lack of molecular diagnostic tests for the confirmation of HIV and HBV could impact the seroprevalence found. In fact, some studies found higher seroprevalence of hepatitis B by performing the HBV viral load and detecting some serological marker such as $\mathrm{HBc}$ antibodies among $\mathrm{HBs}$ antigen negative subject that essential to identify cases of occult hepatitis B. ${ }^{33,34}$

\section{Conclusion}

The seroprevalence of HIV and HBV remain high among pregnant women attending Guelendeng Health District with age, blood transfusion and the non-use of condom as risk factors. We should emphasize on those factor-prevention related strategies to curb the HIV and HBV spread in the republic of Chad.

\section{Ethical considerations and consent to participate}

The current study was conducted under the academic research thesis at the Higher Institute of Health Professionals of the University of Douala, with clearance obtained from the University Institutional Review Board (IRB), reference: ATTESTATION DE RECHERCHE $\mathrm{N}^{\circ} 009 / \mathrm{AR} / \mathrm{ISPS} / \mathrm{P} / \mathrm{D} / \mathrm{Scol}$. Administrative authorization was issued by the Chief District Officer of the Guelendeng Health District (No 001/PR/MSP/DG/DSPMKE/HDSG/2019). Also, each woman enrolled in this study was first subject to an information notice, then an informed consent (written informed consent from adult or guardian for children) card and finally to an anonymized questionnaire guaranteeing confidentiality. In addition, pre and post test counseling was provided to all participants.

\section{Acknowledgements}

Our gratitude goes towards all pregnant women who agreed to participate in this study and Guelendeng Health District staff for the collaboration.

\section{Conflicts of interest}

The authors declare that they have no conflict of interest.

\section{Funding}

No funding was received.

\section{References}

1. Matthews PC, Geretti AM, Goulder PJ, et al. Epidemiology and impact of HIV co-infection with hepatitis B and hepatitis C viruses in SubSaharan Africa. J ClinVirol. 2014;61(1):20-33.

2. UNAIDS, Global Report: UNAIDS report on the global AIDS epidemic 2013. Geneva, Switzerland; 2013.

3. Gaeta GB, Precone DF, Cozzi-Lepri A, et al. Multiple viral infections. $J$ Hepatol. 2006;44 (Suppl 1):S108-113.

4. Nikolopoulos GK, Paraskevis D, Hatzitheodorou E, et al. Impact of Hepatitis B Virus Infection on the Progression of AIDS and Mortality in HIV-Infected Individuals: A Cohort Study and Meta-Analysis. Clin Infect Dis. 2009;48(12):1763-1771.

5. Graham CS, Baden LR, Yu E, et al. Influence of human immunodeficiency virus infection on the course of hepatitis $\mathrm{C}$ virus infection: a metaanalysis. Clin Infect Dis. 2001;33(4):562-569.

6. Mallet V, Vallet-PichardA, PolS. The impact of human immunodeficiency virus on viral hepatitis. Liver Int. 2011;31(Suppl 1):135-139.

7. UNAIDS Global report on the AIDS epidemic 2010. Geneva; 2010 .

8. Taylor LE, Swan T, Mayer KH. HIV co-infection with hepatitis C virus: evolving epidemiology and treatment paradigms. Clin Infect Dis. 2012;55(Suppl 1):S33-S42.

9. Platt L, Easterbrook P, Gower E, et al. Prevalence and burden of HCV co-infection in people living with HIV: a global systematic review and meta-analysis. Lancet Infect Dis. 2016;16(7):797-808.

10. Sogni P, Bacq Y. Prevent mother-to-child transmission of HBV. La Revue du Praticien (General Medicine). 2012;885:547-548.

11. Frambo AA, Atashili J, Fon PN, et al. Prevalence of HBsAg and knowledge about hepatitis B in pregnancy in the Buea Health District. Cameroon: a cross-sectional study. BMC Research Notes. 2014;7:394 
12. Lee C, Gong Y, Brok J, et al. Effect of hepatitis B immunisation in newborn infants of mothers positive for hepatitis B surface antigen: systematic review and meta-analysis. BMJ. 2006;332(7537):328-336.

13. Hamdani-Belghiti S, Bouazzaou NL. Mother-to-child transmission of hepatitis B virus. Status of the problem and prevention. ArchPediatr. 2000;7:879-882.

14. PND. Chad National Development Plan, PND communication strategy. 2013-2015.

15. HIV - AIDS: prevention, diagnosis and treatment.

16. Celine Nguefeu Nkenfou, Japhette Esther Kembou, Edith Saounde Temgoua, et al. Evaluation of ORAQUICK ${ }^{\circledR} \mathrm{HIV}-1 / 2$ as oral rapid test. Afr J Infect Dis. 2013;7(2):27-30.

17. WHO. Guidelines on hepatitis B and C testing. Geneva: World Health Organization; 2017.

18. One step Hepatitis B Surface Antigen Test Strip Package Insert. 2018.

19. PSLS. Chad AIDS Response Progress Report. 2012-2013.

20. EDS-MICS. National Institute of Statistics, Economic and Demographic Studies (INSEED) N'Djaména, Chad, Demographic and Health Survey and Multiple Indicators in Chad (EDS-MICS). 2015;655.

21. Julian Suesstrunk, Frederic BernibaDjongali. Hepatitis B virus prevalence in rural in south-west Chad. Trop Doct. 2017;47(4):374-377.

22. Philippe Salomon Nguwoh, Christian Ngounouh Taheu, Armelle Diane Pouanse Bazu, et al. Hepatitis B and C Virus, Human Immunodeficiency Virus Co-infection and Associated Risk Factors among Pregnant Women in Bafia Health District, Cameroon: A cross-sectional study. Second edition of Conference on Liver Disease in Africa 2019 (COLDA 2019) in Cairo, Egypt; 2019.

23. Christian Ngounouh Taheu, Abigaël Dongmo Tewada, Julienne Louise Ekodi, et al. Seroprevalence of Hepatitis B, C Virus, Human Immunodeficiency Virus and Associated Risk Factors among Pregnant Women attending the Dschang District Hospital, West RegionCameroun. Second edition of Conference on Liver Disease in Africa 2019 (COLDA 2019) in Cairo, Egypt; 2019.
24. Zoulim F. Infectious diseases. Hepatitis B: understanding how the virus persists in the body. 2012.

25. Centers for Disease Control and Prevention. Updated U.S. Public Health Service guidelines for the management of occupational exposures to $\mathrm{HBV}, \mathrm{HCV}$, and $\mathrm{HIV}$ and recommendations for post exposure prophylaxis. $M M W R$. 2001;50(RR-11):1-52.

26. MwumvanezaMutagoma, Helene Balisanga, Samuel S Malamba, et al. Hepatitis B virus and HIV co-infection among pregnant women in Rwand. BMC Infectious Diseases. 2017;17:618.

27. Thumbiran NV, Moodley D, Parboosing R, et al. Hepatitis B and HIV co-infection in pregnant women: indication for routine antenatal hepatitis B virus screening in a high HIV prevalence setting. S Afr Med J. 2014;104(4):307-309.

28. Noubiap JJ, Nansseu JR, Ndoula ST, et al. Prevalence, infectivity and correlates of hepatitis B virus infection among pregnant women in a rural district of the Far North Region of Cameroon. BMC Public Health. 2015;2:15.

29. Sara A Healy, Sonia Gupta, Ann J Melvin. HIV/HBV co-infection in children and antiviral therapy. Expert Rev Anti Infect Ther. 2013;11(3): 251-263.

30. PSN. Programme Statistique National Annuel-INSEED6TCHAD. 2011.

31. CNLS. Rapport de progrès N5 PTME, CNLS, Cameroun; 2010.

32. OluyinkacOladele Opaleye, Adeolu Sunday Oluremi, Adetona Babatunde Atiba, et al. Occulthepatitis b virus infection among HIV positive patients in Nigeria. J Trop Med. 2014;2014:7996121.

33. Ofori-Asenso R, Agyeman A. Hepatitis B in Ghana: a systematic review and meta-analysis of prevalence studies (1995-2015). BMC Infect Dis. 2016;16(1):130

34. N'Dri-Yoman T, Anglaret X, Messou E, et al. Occult HBV infection in untreated HIV-infected adults in Côte d'Ivoire. AntivirTher. 2010;15(7):1029-1034. 